\title{
Composite Actinorhizal Plants with Transgenic Roots for the Study of Symbiotic Associations with Frankia
}

\author{
Faïza Meriem Benabdoun,, 2 Mathish Nambiar-Veetil, ${ }^{1,3}$ Leandro Imanishi, ${ }^{1,4}$ \\ Sergio Svistoonoff, ${ }^{1}$ Nadia Ykhlef, ${ }^{2}$ Hassen Gherbi, ${ }^{1}$ and Claudine Franche ${ }^{1}$ \\ ${ }^{1}$ Institut de Recherche pour le Développement (IRD), 911 avenue Agropolis, BP 64501, 34394 Montpellier Cedex 5, France \\ ${ }^{2}$ Laboratoire de Génétique, Biochimie et Biotechnologies Végétales, Département de Biologie et d'Ecologie, Université Mentouri, \\ Route Ain El Bey, Constantine, Algeria \\ ${ }^{3}$ Institute of Forest Genetics and Tree Breeding, Forest Campus, R. S. Puram, Coimbatore 641002, India \\ ${ }^{4}$ Laboratorio de Bioquímica, Microbiología e Interacciones Biológicas en el Suelo (LBMIBS), Departamento de Ciencia y Tecnología, \\ Universidad Nacional de Quilmes, R. Sáenz Peña 352, Bernal B1876BXD, Argentina
}

Correspondence should be addressed to Claudine Franche, claudine.franche@ird.fr

Received 8 July 2011; Accepted 24 August 2011

Academic Editor: Johann Greilhuber

Copyright (c) 2011 Faïza Meriem Benabdoun et al. This is an open access article distributed under the Creative Commons Attribution License, which permits unrestricted use, distribution, and reproduction in any medium, provided the original work is properly cited.

\begin{abstract}
More than 200 species of dicotyledonous plants belonging to eight different families and 24 genera can establish actinorhizal symbiosis with the nitrogen-fixing soil actinomycete Frankia. Compared to the symbiotic interaction between legumes and rhizobia, little is known about the molecular basis of the infection process and nodule formation in actinorhizal plants. Here, we review a gene transfer system based on Agrobacterium rhizogenes that opens the possibility to rapidly analyze the function of candidate symbiotic genes. The transformation protocol generates "composite plants" that consist of a nontransgenic aerial part with transformed hairy roots. Composite plants have already been obtained in three different species of actinorhizal plants, including the tropical tree species Casuarina glauca, the Patagonian shrub Discaria trinervis, and the nonwoody plant Datisca glomerata. The potential of this technique to advancing our understanding of the molecular mechanisms underlying infection by Frankia is demonstrated by functional analyses of symbiotic genes.
\end{abstract}

\section{Introduction}

Actinorhizal plants have the ability to form root nodules in symbiotic association with the soil actinomycete Frankia and are capable of high rates of nitrogen fixation, comparable to those of legumes [1-3]. More than 200 species of dicotyledonous plants, belonging to eight different families and 24 genera, can establish actinorhizal symbioses. They are trees and woody shrubs, such as Alnus, Casuarina, Eleagnus, and Myrica, with one exception, the nonwoody species Datisca. They are distributed throughout temperate and tropical regions and, due to their ability to grow on poor and degraded soils, are often pioneer species. Like Legumes, actinorhizal symbioses can add a large amount of fixed nitrogen to several ecosystems including temperate forests, sandy tropical areas, and mine wastes. In symbiotic association with both Frankia and mycorrhizal fungi, actinorhizal trees can help rehabilitate degraded areas and are also used in forestry for the production of timber and pulpwood, to stabilize desert and coastal dunes, and crop windbreak [4-6].

Possibly due to their wide range of host plants, actinorhizal nodules show considerable variability in structure, oxygen protection mechanisms, and physiology, making it difficult to choose a single model actinorhizal plant to acquire the necessary basic knowledge on the symbiotic interaction with Frankia. In recent years, molecular and genomic studies have mainly focused on three actinorhizal species including two trees, the tropical species Casuarina glauca and the temperate species Alnus glutinosa, plus the herbaceous species Datisca glomerata [7-10]. Both C. glauca 
and A. glutinosa are infected by Frankia via an intracellular process involving penetration into deformed root hairs [1113]. In D. glomerata, although the colonization process is not fully understood, the nodulation process is likely to occur via intercellular colonization of the host root [14].

The recent development of transcriptomics in actinorhizal plants has led to the identification of many candidate genes that could play a key role in different stages of the symbiotic process $[9,10]$. The production of genetically modified actinorhizal plants is a prerequisite for the molecular and physiological analysis of gene function during the symbiotic interaction with Frankia. However, developing a genetic transformation procedure based on A. tumefaciens is often challenging since it requires both an efficient gene transfer protocol and the development of a reliable in vitro regeneration method. With the exception of the two Casuarinaceae trees, Allocasuarina verticillata [15] and C. glauca [16] in which stable genetic transformation has been achieved using the disarmed strain of A. tumefaciens C58C1 [17], there are no other reports of stably transformed actinorhizal plants [18].

Agrobacterium rhizogenes could provide an alternative to the labor intensive genetic transformation by A. tumefaciens. A. rhizogenes is a gram-negative soil bacterium responsible for the development of hairy root disease in a number of dicotyledonous plants [19]. It transfers into the genome of the infected host plant a T-DNA fragment from the bacterial root-inducing ( $\mathrm{Ri}$ ) plasmid that carries genes encoding enzymes that control auxin and cytokinin biosynthesis [20]. The resulting modifications in the hormonal balance induce the formation of roots at the wounding site that are morphologically different from normal roots. Hairy roots are characterized by a rapid hormone-independent growth, are much more highly branched, possess numerous root hairs, and exhibit plagiotropic root development. A. rhizogenes has proven to be a valuable tool for generating transgenic roots that are easy to grow and can be used for a range of applied biological purposes including metabolic engineering and phytoremediation, and the production of valuable metabolites [21].

A. rhizogenes hairy roots have other applications in many areas of research including symbiotic nitrogen fixation where they provide a tool for root nodule studies. This pathogenic bacterium can be used to generate composite plants consisting of transformed hairy roots induced on a nontransgenic shoot $[22,23]$. This procedure allows a more rapid analysis of transformed roots than the methods used to generate plants that are stably transformed by $A$. tumefaciens. The approach was first used in Legumes to study the symbiotic interaction with rhizobia. Transformation techniques that generate composite plants have been then reported for Lotus corniculatus [23], Trifolium rupens [24], Vigna aconitifolia [25], Glycine max [26-28], Vicia hirsuta [29], Lotus japonicus [30], Trifolium pratense [31], Medicago truncatula [32], Lupinus albus [33], Phaseolus vulgaris [34, 35], Arachis hypogea [36], and Aeschynomene indica [37].

Composite plants appear to be a suitable tool for functional analysis of the symbiotic genes in actinorhizal plants. Since most actinorhizal plants are trees or shrubs, developing
TABLE 1: Induction of hairy roots by A. rhizogenes on actinorhizal plants.

\begin{tabular}{lcc}
\hline Actinorhizal plants & Strains of A. rhizogenes & References \\
\hline $\begin{array}{l}\text { Alnus glutinosa, Alnus } \\
\text { acuminata }\end{array}$ & A4, 1855, 8196, K599 & {$[38]$} \\
Elaeagnus angustifolia & K599 & {$[38]$} \\
Allocasuarina verticillata & A4RS, 8196, 2659 & {$[42]$} \\
Casuarina glauca & A4RS, ARqual & {$[43,44]$} \\
Datisca glomerata & LBA 1334 & {$[45]$} \\
Discaria trinervis & A4RS, ARqua1 & {$[46]$} \\
\hline
\end{tabular}

rapid genetic transformation procedures to generate data on candidate symbiotic genes is of particular interest. In the present paper, we review transformation methods in which A. rhizogenes has been used in actinorhizal species. Recent advances in knowledge of the Frankia infection process based on the use of composite plants have been described.

\section{Agrobacterium rhizogenes-Mediated Transformation of Actinorhizal Plants}

2.1. Susceptibility of Actinorhizal Plants to A. rhizogenes. A. rhizogenes-mediated transformation was first described in the actinorhizal plants Alnus glutinosa, A. acuminata, and Elaeagnus angustifolia [38]. Inoculations were performed with two agropine-type strains, A4 [39] and 1855 [40], the manopine-type strain 8196 [41] and the cucumopinetype strain K599 [38] (Table 1). Whereas hairy roots were observed on the seedlings of Alnus, the authors reported that nodule-like structures, so called pseudoactinorhizae, proliferated following the inoculation of E. angustifolia with the strain K599.

In 1991, it was subsequently shown that A. verticillata, a member of the Casuarinaceae family, was susceptible to three different strains of A. rhizogenes, A4, 8196, and 2659, a cucumopine-type strain [47] (Table 1). All three agrobacteria induced hairy roots on inoculated hypocotyls of 30-day-old germinated seedlings [42]. It was noted that shoot regeneration occurred spontaneously in $90 \%$ of the 2659-transformed roots after three months of culture on hormone-free nutrient medium, thereby, allowing the regeneration of fully transformed plants of $A$. verticillata. Since this actinorhizal tree species was not chosen for the isolation of symbiotic genes, the composite plant approach was never developed further.

Due to its small genome size, C. glauca was the species in the Casuarinaceae family chosen to decipher the symbiotic interaction between Frankia and its host at the molecular level. As a result, genetic transformation procedures allowing functional analysis of the candidate symbiotic genes were developed together with the genomic resources. In 1995, Diouf et al. [43] reported that the A. rhizogenes strain A4RS could be used to obtain composite plants that were nodulated by Frankia. The strain of A. rhizogenes ARqua1 [29] that is used to obtain composite plants of M. truncatula [32] has 
also been shown to be effective on C. glauca (H. Gherbi, unpublished data).

More recently, two other actinorhizal plants, the nonwoody plant $D$. glomerata, and Discaria trinervis, a shrub from Patagonia [48], were shown to be effectively transformed by $A$. rhizogenes to generate hairy roots $[45,46]$ (Table 1). Composite plants of D. glomerata were generated using the A. rhizogenes strain LBA 1334 [49]. In D. trinervis, both A4RS and ARqual induced transgenic roots in wounded plants, but they differed in their phenotype because the genetic transformation by A4RS had a strong impact on the alteration of root architecture [46].

2.2. Transformation Procedures. Inoculations with A. rhizogenes involve wounding on the hypocotyls of young seedlings with a needle dipped in a fresh colony (or culture in exponential growth) of the chosen $A$. rhizogenes strain. This technique was successful in A. glutinosa, A. acuminata, A. verticillata, $C$. glauca, and D. trinervis. In D. glomerata, an original transformation system consisted of injecting the agrobacterium culture into the stem of 12 -week-old plants [45].

In C. glauca, an alternative procedure consisted in sectioning the radicle of the seedlings with a scalpel and then coating the sectioned surface with A. rhizogenes. However, hairy roots developed in less than $30 \%$ of the sectioned plants, whereas when hypocotyls were inoculated with a needle, hairy roots developed in $95 \%$ of the plants.

To generate composite plants, the normal nontransformed root system is removed from the actinorhizal plants about three weeks after inoculation with A. rhizogenes, and, when possible, cotransformed roots containing the newly introduced genes from the appropriate binary vector are selected. The whole process of generating composite actinorhizal plants takes 2-3 months. It then takes an additional 2-3 months to perform the nodulation or mycorrhization experiments [43]. In C. glauca, it was observed that, although the shoot was not transgenic, composite plants exhibited an altered aerial part with shorter internodes. This alteration of phenotype is probably linked to the modification of the hormonal balance in the transgenic root system displaying the hairy root phenotype.

2.3. Selection of Cotransformed Hairy Roots. One advantage of $A$. rhizogenes-mediated transformation is that transgenic roots can be obtained without using a selection agent. Hairy root morphology is used for the primary selection of transgenic root. However, when performing a cotransformation with an $A$. rhizogenes strain harboring a binary vector, a selection procedure with either a reporter gene or an antibiotic resistance gene is usually necessary to detect the cotransformed roots and to facilitate molecular and phenotypic analyses of the composite plants. According to our experience with $C$. glauca, following the analysis of several hundred of composite plants, the rate of cotransformed hairy roots could vary from $20 \%$ to $65 \%$. In order to identify the cotransformed roots, a constitutively expressed reporter gene such as $\beta$-glucuronidase (GUS) [52], DsRED1 [53], or green fluorescent protein (GFP) [54] gene can be included in the TDNA of the binary vector. DsRED1 and GFP appeared to be the best candidates since they can be visualized in roots under UV light. DsRED1 fluorescence was chosen to select the cotransformed roots of $D$. glomerata emerging at the sites of inoculation with LBA 1334 [45]. In C. glauca and D. trinervis, cotransformation events were usually monitored with GFP fluorescence $[44,46]$. The intensity of fluorescence was generally correlated with the level of expression of the other genes carried on the T-DNA of the binary vector. In RNAi experiments designed to downregulate symbiotic genes in $C$. glauca, hairy roots displaying a high level of fluorescence also exhibited a strong extinction of the candidate symbiotic gene as determined by q-RTPCR (H. Gherbi, unpublished data).

Kanamycin selection of cotransformed roots of C. glauca has occasionally been performed using the nptII gene in the transferred T-DNA. A range of kanamycin concentrations was tested to inhibit the growth of noncotransformed hairy roots on agar plates. A concentration of $12.5 \mathrm{mg}$ per liter was found to be sufficient to alter the growth of roots deprived of the nptII gene without affecting the nontransformed shoot. After three weeks of incubation with kanamycin, the noncotransformed roots were gray whereas the cotransformed roots remained pink and continued to undergo rapid growth in the agar. However, once the composite plants were transferred in hydropony for nodulation experiments with Frankia, the selection with kanamycin could not be applied, and the noncotransformed roots could grow due to the long kinetics experiments of nodulation in actinorhizal plants (23 months in RNAi experiments).

2.4. Nodulation of Actinorhizal Composite Plants. Hairy root morphology in plants varies considerably between species with differences in root thickness, degree of branching, and amount of root hair production. The differences in response to A. rhizogenes infection could be due to combined factors resulting from genotype-strain interactions, response to rol gene products, together with the effects of endogenous and exogenous hormones [20]. In the actinorhizal tree C. glauca, A4RS-induced hairy roots exhibited a marked hairy root phenotype [43]. It was found that the nodulation process was affected since only $30 \%$ to $60 \%$ of the composite plants developed nodules after inoculation with Frankia, whereas $90 \%$ to $100 \%$ of the nontransformed plants were nodulated. Although hairy roots usually tend to have very profuse root hairs, composite plants of C. glauca have fewer root hairs, which possibly affected the efficiency of nodulation. In addition, the nodulation process was often delayed by about two weeks. However, nodules that developed on composite plants were found to fix nitrogen, and their anatomy resembled that of nontransformed control nodules, making it possible to use this approach for promoter and RNAi studies. With the ARqual strain, the hairy-root phenotype was less pronounced in C. glauca, but this had no significant impact on the efficiency of nodulation by Frankia.

In $D$. trinervis, the nodulation process was not affected in composite plants resulting from the inoculation with ARqua1 [46]. Nodules exhibited the same structural features 
as those of control plants. Furthermore, the negative regulation of nodulation by nitrogen was maintained in the transgenic roots since the addition of $\mathrm{NH}_{4} \mathrm{NO}_{3}$ at $100 \mathrm{ppm}$ was found to inhibit nodule formation in composite plants. In $D$. glomerata, the possible alteration of the nodulation resulting from the expression of the oncogenes of A. rhizogenes LBA 1335 was not reported by the authors [45].

\section{Studies of the Infection Process}

Actinorhizal nodules only develop under conditions of nitrogen deprivation, and it is assumed that plant roots emit signals of still unknown nature that are perceived by Frankia. To date, the early stages of this original nodulation process remains rather poorly known [55-58]. In particular, the lack of a genetic transformation system in Frankia has prevented the introduction of a $g f p$ gene that would allow visualisation of the progression of the hyphae in the host $[59,60]$. The early stages of the infection process can thus be studied mainly by the analysis of transgenic roots expressing reporter genes under the control of promoters from early expressed symbiotic genes.

Two promoters, PCg12 and PMtEnod11, have been found to drive the reporter gene in Frankia-infected cells. Cg12 is an actinorhizal symbiotic gene isolated from C. glauca [61] that encodes a subtilisin-like serine protease (subtilase). Plant subtilases are represented by large gene families and have been shown to be involved in stomata and seed development, in the maintenance of the shoot apical meristem and of the cell wall, in the processing of peptide growth factors, and in response to the biotic and abiotic environment [62]. Using roots of C. glauca genetically transformed with a PCg12-GUS or a PCg12-GFP construct, it was shown that reporter gene expression occurred during the first steps of the infection process, when Frankia was invading deformed root hairs and in root and nodule cortical cells containing growing infection threads [63]. Cg12 expression was correlated with plant cell invasion by the endosymbiont from the start of the symbiotic process, thereby, providing a valuable tool to visualize and count the number of infected root hairs, and subsequently to monitor the progression of the hyphae in the plant root. This promoter is currently being introduced into $D$. trinervis to monitor the progression of Frankia hyphae during the intercellular infection process (S. Svistoonoff and L. Wall, unpublished data).

The second sequence is PMtEnod11, the promoter region from the early nodulin gene MtEnod11 from $M$. truncatula [64]. In legumes, PMtEnod11-GUS is transcribed in the root epidermis in response to Nod factors, during preinfection and infection stages of root and nodule tissues [32]. It is also expressed during endomycorrhization, thereby, providing a valuable tool to study the initial stages of endosymbiotic interactions [65]. Interestingly, it was found that, in $C$. glauca plants transformed with PMtEnod11-GUS, although no induction was observed in the root epidermis, reporter gene expression was conserved in the infected zones of the roots and actinorhizal nodules [66]. The same construct was introduced using the composite plant approach in
D. trinervis. In the nodules, GUS activity was observed in the infection zone, in cortical cells infected by Frankia that do not yet fix nitrogen [46]. Therefore, this heterologous promoter from a legume is an additional tool to monitor both intracellular and intercellular infection processes in actinorhizal plants.

\section{RNAi to Downregulate Actinorhizal Symbiotic Genes}

The development of genetic and genomic tools for the model legumes M. truncatula and Lotus japonicus has contributed to the isolation and characterization of genes required for root nodule symbiosis $[65,67,68]$. Some of these genes have been designated as "common Sym" genes since they are involved in the establishment of both rhizobia and mycorrhizal symbioses. The "common Sym pathway" includes genes encoding a leucine-rich-repeat (LRR) receptor kinase $(S y m R K)$, cation channels, nuclear pore complex proteins, a calcium and calmodulin-dependent protein kinase (CCaMK), a nuclear coiled protein, and a transcription factor (NSP1) [68]. The question was whether these symbiotic genes were shared in the signal transduction pathway in response to Frankia factors.

To answer this question, studies focused on the receptorlike kinase gene SymRK and based on RNAi experiments using composite plants were undertaken in both $C$. glauca and in D. glomerata. In legumes, SymRK (also referred to as NORK in Medicago sativa and DMI2 in M. truncatula) encodes a leucine-rich receptor kinase that is needed for bacterial and endomycorrhizal infection, and Nod factor induced calcium spiking in the root epidermis [6971]. Based on similarity with legume $S y m R K$ sequences, CgSymRK and DgSymRK were isolated from C. glauca and D. glomerata, respectively. Downregulation of both actinorhizal SymRK genes resulting from a RNAi approach revealed that the frequency of nodulated RNAi-CgSymRK and RNAi$D g S y m R K$ plants was dramatically reduced compared to that in control plants. In C. glauca, a two-fold reduction in the number of nodulated plants was observed [51], and in $D$. glomerata, only $16 \%$ of the transformed roots exhibited some nodule-like structures [45]. In addition, a range of morphological alterations was observed in the downregulated SymRK nodules. Whereas mature nodules in the control C. glauca plants were multilobed, RNAi nodules were considerably reduced in size and consisted, in the strongly silenced lines, of a single thin lobe that did not fix nitrogen and had a very short nodular root [51]. Cytological analysis showed that these aberrant nodular structures accumulated high levels of phenolic compounds and contained cortical infected cells that were smaller than those of control nodular lobes. In D. glomerata, small primordial swellings were occasionally observed when Frankia infection was able to proceed due to incomplete downregulation of $D g S y m R K$.

Additional experiments revealed that $S y m R K$ was also necessary for the establishment of the symbiosis with the arbuscular mycorrhiza Glomus intraradices in actinorhizal plants. The knockdown of both CgSymRK and DgSymRK 
was seen to strongly affect penetration of the fungal hyphae into the root cortex, thus, revealing the key role of SymRK in root endosymbioses for both C. glauca and D. glomerata $[45,51]$.

The conservation of the SymRK function between legumes and actinorhizal plants could reflect a common genetic program for endosymbiosis development and suggests that, during their evolution, root nodule endosymbioses recruited the genes necessary for arbuscular mycorrhizal symbiosis. To further investigate the conservation of the common Sym pathway in actinorhizal plants, additional studies to functionally characterize $C$. glauca sequences homologous to the calmodulin-dependent protein kinase $(C C a M K)$ gene are in progress using the composite plant system.

\section{Knowledge Generated by Composite Plants Derived from Shoots Stably Transformed by A. tumefaciens}

Genetic transformation of $C$. glauca can also be achieved using the A. tumefaciens strain C58C1 (pGV2260) [16], and stably transformed plants can be regenerated in six to nine months. Using transgenic shoots, it was possible to induce hairy roots after inoculation by $A$. rhizogenes and hence to introduce a second set of genes in the root system for additional study.

We used this procedure to study the impact of the downregulation of $C g C C a M K$ on the number of infection sites following inoculation by Frankia. CgCCaMK was isolated in C. glauca and is homologous with the calmodulin-dependent protein kinase genes from Legumes [72, 73]. In absence of a GFP-expressing Frankia strain, transgenic PCg12-GUS plants are the best tools to visualize and count the infection sites during the early stages of the symbiotic process [63]. PCg12-GUS transgenic shoots were retransformed by $A$. rhizogenes A4RS containing in a binary vector the RNAiCgCCaMK construct and a 35S-GFP transcriptional fusion, and then inoculated by the Frankia strain CcI3. Control plants included PCg12-GUS shoots transformed with A4RS. Seven to 10 days after inoculation, a GUS test was performed on the whole GFP-positive hairy-root systems to locate blue-stained infected root hairs [46]. Total root length was measured and that and the number of blue root hairs were compared with data obtained in the control hairy roots. The average number of blue hairs per $\mathrm{cm}$ of root decreased about 10-fold in RNAi-CgCCaMK hairy roots compared to the number in the control composite plants, revealing the essential role of $\mathrm{CgCCaMK}$ in the root hair infection process by Frankia (H. Gherbi, unpublished data).

Functional analysis of CgAUX1, a gene that encodes a high-affinity auxin influx transporter in C. glauca, also produced interesting results. Using the GUS gene driven by the $C g A U X 1$ promoter, it was established that auxin plays an important role during plant cell infection in actinorhizal symbiosis [72]. CgAUX1-GUS was found to be strongly expressed both during root hair infection and cortical cell invasion by Frankia. In mature nodules, strong reporter gene expression was observed in the nodule vascular system

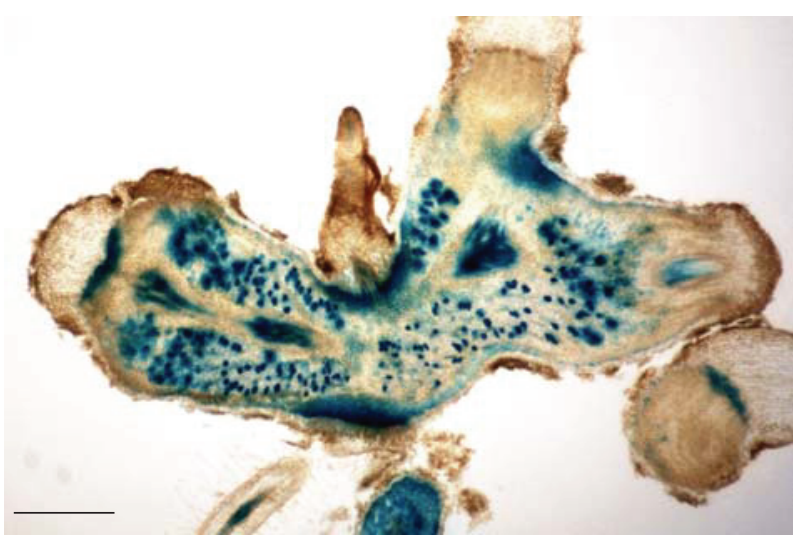

(a)

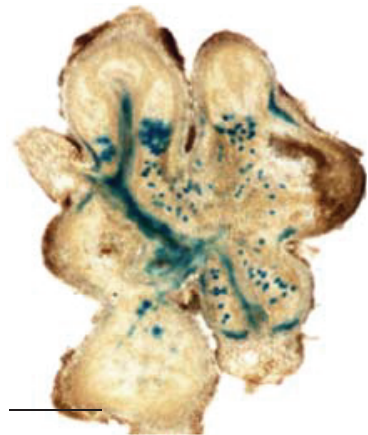

(b)

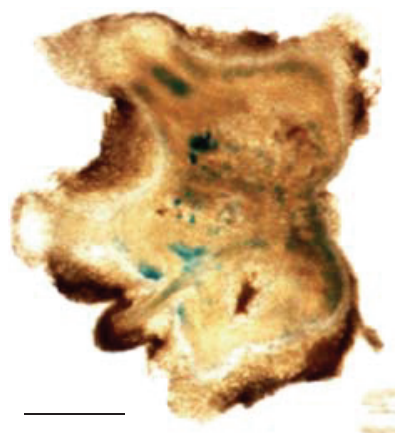

(c)
FIGURE 1: $\beta$-glucuronidase expression in hairy roots of AUX1-GUS C. glauca plants silenced with a RNAi-CgSymRK construct. AUX1GUS plants were obtained after genetic transformation with the strain of A. tumefaciens C58C1 as described in [50], and transgenic shoots were then inoculated with a strain of A. rhizogenes A4RS containing either an empty vector (a) or a vector with a $35 S$ CgSymRK-hairpin construct to downregulate the expression of the receptor-like kinase gene $\operatorname{SymRK}$ from C. glauca (b, c) [51]. Composite plants were screened for GFP expression, inoculated with Frankia, and $\beta$-glucuronidase gene expression was studied in $50 \mu \mathrm{m}$ three-week-old nodule sections. (a) In nonsilenced nodules, AUX1-GUS expression was observed in the nodule vascular system, the nodule apical zone at the basis of the nodular root, in the Frankia infected cells, and in the phellogen. (b, c) In the RNAiCgSymRK nodules from two different composite plants, AUX1-GUS expression was found to be strongly affected; a strong alteration of the nodule size correlated with a low residual activity of the reporter gene (c). Bars: $\mathrm{a}=1 \mathrm{~mm}, \mathrm{~b}=500 \mu \mathrm{m}$, and $\mathrm{c}=250 \mu \mathrm{m}$.

and at the base of the nodular root, and in the large cortical cells infected by Frankia, corresponding to the nitrogenfixation zone; some reporter gene activity was also observed in the nodule secondary meristem corresponding to the phellogen (Figure 1(a)). When CgAUX1-GUS plants obtained after genetic transformation by A. tumefaciens were retransformed with the A. rhizogenes strain A4RS containing a RNAi-CgSymRK construct [70], a major alteration of the CgAUX1-GUS expression was observed in the small nodules whose phenotype was deeply altered by downregulation of CgSymRK (Figures 1(b) and 1(c)). The blue staining was hardly visible in the infected cortical cells; reporter gene 
expression was also greatly reduced in the phellogen and in the apex of the nodule. These data indicate a strong alteration of CgAUX1 expression linked to the low expression of the receptor kinase gene $C g S y m R K$. A disturbance of the influx of auxin could be involved in the modification of the phenotype of the RNAi nodules. The smallest nodules were observed on composite plants exhibiting a strong GFP fluorescence. These nodular structures were characterized by a low $A U X 1$-driven reporter gene expression and by the absence of nodular root (Figure 1(c)).

\section{Conclusions}

The potential of $A$. rhizogenes to investigate the nitrogen fixing interactions between Frankia and actinorhizal plants has been shown in C. glauca, a member of the Casuarinaceae family [47], in D. glomerata, a member of the Datiscaceae [43], and in D. trinervis, a member of the Rhamnaceae [48]. These actinorhizal plants are characterized by either intracellular or intercellular infection processes; they exhibit nodules with different structures and are infected by specific strains of Frankia. Composite plants provide a valuable and fast strategy to downregulate or overexpress putative symbiotic genes and to acquire fundamental knowledge on their role during infection and nodule ontogenesis in these diverse nitrogen-fixing plants. This knowledge will certainly help understand the wide range of molecular mechanisms underlying the actinorhizal nodulation process in different plant families.

\section{Acknowledgments}

This work was supported by the Institut de Recherche pour le Développement (IRD) and by the Agence Nationale de la Recherche (ANR) Blanc project NewNod (ANR-06-BLAN0095) and SESAM (BLAN-1708-01), by the ECOS-SUD project A07B02 and Bernardo Houssay program (2998). F. M. Benabdoun was supported by a Ph.D. grant from Averroes program (EU). M. Nambiar-Veetil was financially supported by a grant from the Department of Biotechnology, Ministry of Science and Technology, Government of India. L. Imanishi was supported by the IRD Department of Capacity-Building for Southern Scientific Communities (IRD-DPF), University of Quilmes, and the Argentinean National Research Council (CONICET).

\section{References}

[1] L. G. Wall, "The actinorhizal symbiosis," Journal of Plant Growth Regulation, vol. 19, no. 2, pp. 167-182, 2000.

[2] J. O. Dawson, "Ecology of actinorhizal plants," in NitrogenFixing Actinorhizal Symbioses-Nitrogen Fixation Research: Origins and Progress, K. Pawlowski and W. E. Newton, Eds., vol. 6, pp. 199-234, Springer, New York, NY, USA, 2008.

[3] C. Franche, K. Lindström, and C. Elmerich, "Nitrogen-fixing bacteria associated with leguminous and non-leguminous plants," Plant and Soil, vol. 321, no. 1-2, pp. 35-59, 2009.

[4] J. O. Dawson, "Actinorhizal plants: their use in forestry and agriculture," Outlook on Agriculture, vol. 15, no. 4, pp. 202208, 1986.
[5] H. G. Diem and Y. R. Dommergues, "Current and potential uses and management of Casuarinaceae in the tropics and subtropics," in The Biology of Frankia and Actinorhizal Plants, R. Schwintzer and 1. D. Tjepkema, Eds., pp. 317-342, Academic Press, San Diego, Calif, USA, 1990.

[6] C. Zhong, Y. Zhang, Y. Chen et al., "Casuarina research and applications in China," Symbiosis, vol. 50, no. 1-2, pp. 107$114,2010$.

[7] L. Laplaze, S. Svistoonoff, C. Santi, F. Auguy, C. Franche, and D. Bogusz, "Molecular biology of actinorhizal symbioses," in Nitrogen Fixation Research: Origins and Progress, K. Pawlowski and W. E. Newton, Eds., vol. 6, pp. 235-259, Springer, New York, NY, USA, 2008.

[8] K. Pawlowski, "Induction of actinorhizal nodules by Frankia," in Prokarytic Symbionts in Plants, Microbiol Monographs, K. Pawlowski, Ed., vol. 8, pp. 127-154, Springer, Berlin, Germany, 2009.

[9] V. Hocher, F. Auguy, X. Argout, L. Laplaze, C. Franche, and D. Bogusz, "Expressed sequence-tag analysis in Casuarina glauca actinorhizal nodule and root," New Phytologist, vol. 169, no. 4, pp. 681-688, 2006.

[10] V. Hocher, N. Alloisio, F. Auguy et al., "Transcriptomics of actinorhizal symbioses reveals homologs of the whole common symbiotic signaling cascade," Plant Physiology, vol. 156, no. 2, pp. 700-711, 2011.

[11] D. Callaham, W. Newcomb, J. G. Torrey, and R. L. Peterson, "Root hair infection in actinomycete-induced root nodule initiation in Casuarina, Myrica and Comptonia," Botanical Gazette, vol. 140, pp. S1-S9, 1979.

[12] A. M. Berry, L. McIntyre, and M. E. McCully, "Fine structure of root hair infection leading to nodulation in the FrankiaAlnus symbiosis," Canadian Journal of Botany, vol. 64, no. 2, pp. 292-305, 1986.

[13] A. M. Berry and L. A. Sunnel, "The infection process and nodule development," in The Biology of Frankia and Actinorhizal Plants, C. R. Schwintzer and J. D. Tjepkema, Eds., pp. 61-81, Academic Press, New York, NY, USA, 1990.

[14] R. H. Berg, B. Langenstein, and W. B. Silvester, "Development in the Datisca-Coriaria nodule type," Canadian Journal of Botany, vol. 77, no. 9, pp. 1334-1350, 1999.

[15] C. Franche, D. Diouf, Q. V. Le et al., "Genetic transformation of the actinorhizal tree Allocasuarina verticillata by Agrobacterium tumefaciens," Plant Journal, vol. 11, no. 4, pp. 897-904, 1997.

[16] A. Smouni, L. Laplaze, D. Bogusz et al., "The 35S promoter is not constitutively expressed in the transgenic tropical actinorhizal tree Casuarina glauca," Functional Plant Biology, vol. 29, no. 5, pp. 649-656, 2002.

[17] G. Vancanneyt, R. Schmidt, A. O’Connor-Sanchez, L. Willmitzer, and M. Rocha-Sosa, "Construction of an introncontaining marker gene: splicing of the intron in transgenic plants and its use in monitoring early events in Agrobacteriummediated plant transformation," Molecular and General Genetics, vol. 220, no. 2, pp. 245-250, 1990.

[18] S. Svistoonoff, H. Gherbi, M. Nambiar-Veetil et al., "Contribution of transgenic Casuarinaceae to our knowledge of the actinorhizal symbioses," Symbiosis, vol. 50, no. 1-2, pp. 3-11, 2010.

[19] D. Tepfer, "Genetic transformation using Agrobacterium rhizogenes," Physiologia Plantarum, vol. 79, pp. 140-146, 1990.

[20] M. T. Britton, M. A. Escobar, and M. Dandekar, "The oncogenes of Agrobacterium tumefaciens and Agrobacterium rhizogenes," in Agrobacterium: From Biology to Biotechnology, T. Tzfira and V. Citovsky, Eds., pp. 525-563, Springer, 2008. 
[21] S. Guillon, J. Trémouillaux-Guiller, P. K. Pati, M. Rideau, and P. Gantet, "Hairy root research: recent scenario and exciting prospects," Current Opinion in Plant Biology, vol. 9, no. 3, pp. 341-346, 2006.

[22] K. H. Beach and P. M. Gresshoff, "Characterization and culture of Agrobacterium rhizogenes transformed roots of forage legumes," Plant Science, vol. 57, no. 1, pp. 73-81, 1988.

[23] J. Hansen, J. E. Jørgensen, J. Stougaard, and K. A. Marcker, "Hairy roots-a short cut to transgenic root nodules," Plant Cell Reports, vol. 8, no. 1, pp. 12-15, 1989.

[24] C. L. Díaz, P. C. van Spronsen, R. Bakhuizen, G. J. J. Logman, E. J. J. Lugtenberg, and J. W. Kijne, "Correlation between infection by Rhizobium leguminosarum and lectin on the surface of Pisum sativum L. roots," Planta, vol. 168, no. 3, pp. 350-359, 1986.

[25] N. G. Lee, B. Stein, H. Suzuki, and D. P. S. Verma, "Expression of antisense nodulin-35 RNA in Vigna aconitifolia transgenic root nodules retards peroxisome development and affects nitrogen availability to the plant," Plant Journal, vol. 3, no. 4, pp. 599-606, 1993.

[26] C. Cheon, N. G. Lee, A. B. M. Siddique, A. K. Bal, and D. P. S. Verma, "Roles of plant homologs of Rab1p and Rab7p in the biogenesis of the peribacteroid membrane, a subcellular compartment formed de novo during root nodule symbiosis," EMBO Journal, vol. 12, no. 11, pp. 4125-4135, 1993.

[27] A. Kereszt, D. Li, A. Indrasumunar et al., "Agrobacterium rhizogenes-mediated transformation of soybean to study root biology," Nature Protocols, vol. 2, no. 4, pp. 948-952, 2007.

[28] D. Cao, W. Hou, S. Song et al., "Assessment of conditions affecting Agrobacterium rhizogenes-mediated transformation of soybean," Plant Cell, Tissue and Organ Culture, vol. 96, no. 1, pp. 45-52, 2009.

[29] H. J. Quandt, A. Pühler, and I. Broer, "Transgenic root nodules of Vicia hirsuta: a fast and efficient system for the study of gene expression in indeterminate-type nodules," Molecular PlantMicrobe Interactions, vol. 6, no. 6, pp. 699-706, 1993.

[30] J. Stiller, L. Martirani, S. Tuppale, R. J. Chian, M. Chiurazzi, and P. M. Gresshoff, "High frequency transformation and regeneration of transgenic plants in the model legume Lotus japonicus," Journal of Experimental Botany, vol. 48, no. 312, pp. 1357-1365, 1997.

[31] C. L. Díaz, H. P. Spaink, and J. W. Kijne, "Heterologous rhizobial lipochitin oligosaccharides and chitin oligomers induce cortical cell divisions in red clover roots, transformed with the pea lectin gene," Molecular Plant-Microbe Interactions, vol. 13, no. 3, pp. 268-276, 2000.

[32] A. Boisson-Dernier, M. Chabaud, F. Garcia, G. Bécard, C. Rosenberg, and D. G. Barker, "Agrobacterium rhizogenestransformed roots of Medicago truncatula for the study of nitrogen-fixing and endomycorrhizal symbiotic associations," Molecular Plant-Microbe Interactions, vol. 14, no. 6, pp. 695700, 2001.

[33] C. Uhde-Stone, J. Liu, K. E. Zinn, D. L. Allan, and C. P. Vance, "Transgenic proteoid roots of white lupin: a vehicle for characterizing and silencing root genes involved in adaptation to P stress," Plant Journal, vol. 44, no. 5, pp. 840-853, 2005.

[34] G. Estrada-Navarrete, X. Alvarado-Affantranger, J. E. Olivares et al., "Agrobacterium rhizogenes transformation of the Phaseolus spp.: a tool for functional genomics," Molecular PlantMicrobe Interactions, vol. 19, no. 12, pp. 1385-1393, 2006.

[35] N. Colpaert, S. Tilleman, M. van Montagu, G. Gheysen, and N. Terryn, "Composite Phaseolus vulgaris plants with transgenic roots as research tool," African Journal of Biotechnology, vol. 7, no. 4, pp. 404-408, 2008.
[36] S. Sinharoy, S. Saha, S. R. Chaudhury, and M. DasGupta, "Transformed hairy roots of Arachis hypogea: a tool for studying root nodule symbiosis in a non-infection thread legume of the Aeschynomeneae tribe," Molecular PlantMicrobe Interactions, vol. 22, no. 2, pp. 132-142, 2009.

[37] K. Bonaldi, H. Gherbi, C. Franche et al., "The Nod factorindependent symbiotic signaling pathway: development of Agrobacterium rhizogenes-mediated transformation for the legume Aeschynomene indica," Molecular Plant-Microbe Interactions, vol. 23, no. 12, pp. 1537-1544, 2010.

[38] M. A. Savka, L. Liu, S. K. Farrand, R. H. Berg, and J. O. Dawson, "Induction of hairy roots or pseudoactinorhizae on Alnus glutinosa, A. acuminata and Eleagnus angustifolia by Agrobacterium rhizogenes," Acta Oecologica, vol. 13, pp. 423431, 1992.

[39] L. Moore, G. Warren, and F. Strobel, "Involvement of a plasmid in the hairy root disease of plants caused by Agrobacterium rhizogenes," Plasmid, vol. 2, no. 4, pp. 617-626, 1979.

[40] M. Cardarelli, L. Spanò, A. de Paolis, M. L. Mauro, G. Vitali, and P. Costantino, "Identification of the genetic locus responsible for non-polar root induction by Agrobacterium rhizogenes 1855," Plant Molecular Biology, vol. 5, no. 6, pp. 385-391, 1985.

[41] J. Koplow, M. C. Byrne, G. Jen, J. Tempé, and M. D. Chilton, "Physical map of the Agrobacterium rhizogenes strain 8196 virulence plasmid," Plasmid, vol. 11, pp. 130-140, 1984.

[42] M. Phelep, A. Petit, L. Martin, E. Duhoux, and J. Tempé, "Transformation and regeneration of a nitrogen-fixing tree, Allocasuarina verticillata Lam," Nature Biotechnology, vol. 9, no. 5, pp. 461-466, 1991.

[43] D. Diouf, H. Gherbi, Y. Prin, C. Franche, E. Duhoux, and D. Bogusz, "Hairy root nodulation of Casuarina glauca: a system for the study of symbiotic gene expression in an actinorhizal tree," Molecular Plant-Microbe Interactions, vol. 8, no. 4, pp. 532-537, 1995.

[44] H. Gherbi, K. Markmann, S. Svistoonoff et al., "SymRK defines a common genetic basis for plant root endosymbioses with arbuscular mycorrhiza fungi, rhizobia, and Frankia bacteria," Proceedings of the National Academy of Sciences of the United States of America, vol. 105, no. 12, pp. 4928-4932, 2008.

[45] K. Markmann, G. Giczey, and M. Parniske, "Functional adaptation of a plant receptor-kinase paved the way for the evolution of intracellular root symbioses with bacteria.," PLoS Biology, vol. 6, no. 3, p. e68, 2008.

[46] L. Imanishi, A. Vayssière, C. Franche, D. Bogusz, L. Wall, and S. Svistoonoff, "Transformed hairy roots of Discaria trinervis: a valuable tool for studying actinorhizal symbiosis in the context of intercellular infection," Molecular Plant MicrobeInteractions, vol. 24, no. 11, pp. 1317-1324, 2011.

[47] E. Davioud, A. Petit, M. E. Tate, M. H. Ryder, and J. Tempé, "Cucumopine-a new T-DNA-encoded opine in hairy root and crown gall," Phytochemistry, vol. 27, no. 8, pp. 2429-2433, 1988.

[48] C. Valverde and L. G. Wall, "Time course of nodule development in the Discaria trinervis (Rhamnaceae)_Frankia symbiosis," New Phytologist, vol. 141, no. 2, pp. 345-354, 1999.

[49] J. Prell and P. Poole, "Metabolic changes of rhizobia in legume nodules," Trends in Microbiology, vol. 14, no. 4, pp. 161-168, 2006.

[50] B. Péret, R. Swarup, L. Jansen et al., "Auxin influx activity is associated with Frankia infection during actinorhizal nodule formation in Casuarina glauca," Plant Physiology, vol. 144, no. 4, pp. 1852-1862, 2007.

[51] H. Gherbi, M. Nambiar-Veetil, C. Zhong et al., "Post-transcriptional gene silencing in the root system of the actinorhizal 
tree Allocasuarina verticillata," Molecular Plant-Microbe Interactions, vol. 21, no. 5, pp. 518-524, 2008.

[52] R. A. Jefferson, T. A. Kavanagh, and M. W. Bevan, "GUS fusions: beta-glucuronidase as a sensitive and versatile gene fusion marker in higher plants," EMBO Journal, vol. 6, no. 13, pp. 3901-3907, 1987.

[53] M. V. Matz, A. F. Fradkov, Y. A. Labas et al., "Fluorescent proteins from nonbioluminescent Anthozoa species," Nature Biotechnology, vol. 17, no. 10, pp. 969-973, 1999.

[54] J. Haselhoff, "GFP variants for multispectral imaging of living cells," in Methods in Cell Biology, S. Kay and K. Sullivan, Eds., vol. 58, pp. 139-151, Academic Press, New York, NY, USA, 1999.

[55] H. Cérémonie, F. Debellé, and M. P. Fernandez, "Structural and functional comparison of Frankia root hair deforming factor and rhizobia Nod factor," Canadian Journal of Botany, vol. 77, no. 9, pp. 1293-1301, 1999.

[56] T. V. Bhuvaneswari and B. Solheim, "Root-hair interactions in actinorhizal symbioses," in Root Hairs-Cell and Molecular Biology, R. W. Ridge and A. M. C. Emons, Eds., pp. 311-327, Springer, 2000.

[57] K. Pawlowski and J. Sprent, "Comparison between actinorhizal and legume symbioses," in Nitrogen-FIxing Actinorhizal Symbiose, K. Pawlowski and W. E. Newton, Eds., pp. 261-288, Springer, Dordrecht, The Netherlands, 2008.

[58] L. G. Wall and A. M. Berry, "Early interactions, infection and nodulation in actinorhizal symbiosis," in Nitrogen-Fixing Actinorhizal Symbioses, K. Pawlowski and W. E. Newton, Eds., pp. 147-166, Springer, Dordrecht, The Netherlands, 2008.

[59] C. Lavire and B. Cournoyer, "Progress on the genetics of the $\mathrm{N}_{2}$-fixing actinorhizal symbiont Frankia," Plant and Soil, vol. 254, no. 1, pp. 125-137, 2003.

[60] K. I. Kucho, K. Kakoi, M. Yamaura, S. Higashi, T. Uchiumi, and M. Abe, "Transient transformation of Frankia by fusion marker genes in liquid culture," Microbes and Environments, vol. 24, no. 3, pp. 231-240, 2009.

[61] L. Laplaze, A. Ribeiro, C. Franche et al., "Characterization of a Casuarina glauca nodule-specific subtilisin-like protease gene, a homolog of Alnus glutinosa ag12," Molecular Plant-Microbe Interactions, vol. 13, no. 1, pp. 113-117, 2000.

[62] R. Rose, A. Schaller, and C. Ottmann, "Structural features of plant subtilases," Plant Signaling and Behavior, vol. 5, no. 2, pp. 180-183, 2010.

[63] S. Svistoonoff, L. Laplaze, F. Auguy et al., "Cg12 expression is specifically linked to infection of root hairs and cortical cells during Casuarina glauca and Allocasuarina verticillata actinorhizal nodule development," Molecular Plant-Microbe Interactions, vol. 16, no. 7, pp. 600-607, 2003.

[64] E. P. Journet, N. El-Gachtouli, V. Vernoud et al., "Medicago truncatula ENOD11: a novel RPRP-encoding early nodulin gene expressed during mycorrhization in arbusculecontaining cells," Molecular Plant-Microbe Interactions, vol. 14, no. 6, pp. 737-748, 2001.

[65] L. H. Madsen, L. Tirichine, A. Jurkiewicz et al., "The molecular network governing nodule organogenesis and infection in the model legume Lotus japonicus," Nature Communications, vol. 1, no. 1, pp. 1-12, 2010.

[66] S. Svistoonoff, M. O. Sy, N. Diagne, D. G. Barker, D. Bogusz, and C. Franche, "Infection-specific activation of the Medicago truncatula Enod11 early nodulin gene promoter during actinorhizal root nodulation," Molecular Plant-Microbe Interactions, vol. 23, no. 6, pp. 740-747, 2010.
[67] G. E. D. Oldroyd and J. A. Downie, "Coordinating nodule morphogenesis with rhizobial infection in legumes," Annual Review of Plant Biology, vol. 59, pp. 519-546, 2008.

[68] H. Kouchi, H. Imaizumi-Anraku, M. Hayashi et al., "How many peas in a pod? Legume genes responsible for mutualistic symbioses underground," Plant and Cell Physiology, vol. 51, no. 9, pp. 1381-1397, 2010.

[69] G. Endre, A. Kereszt, Z. Kevei, S. Mihacea, P. Kaló, and G. B. Kiss, "A receptor kinase gene regulating symbiotic nodule development," Nature, vol. 417, no. 6892, pp. 962-966, 2002.

[70] S. Stracke, C. Kistner, S. Yoshida et al., "A plant receptorlike kinase required for both bacterial and fungal symbiosis," Nature, vol. 417, no. 6892, pp. 959-962, 2002.

[71] W. Capoen, S. Goormachtig, R. de Rycke, K. Schroeyers, and M. Holsters, "SrSymRK, a plant receptor essential for symbiosome formation," Proceedings of the National Academy of Sciences of the United States of America, vol. 102, no. 29, pp. 10369-10374, 2005.

[72] J. Lévy, C. Bres, R. Geurts et al., "A putative $\mathrm{Ca}^{2+}$ and calmodulin-dependent protein kinase required for bacterial and fungal symbioses," Science, vol. 303, no. 5662, pp. 1361-1364, 2004.

[73] R. M. Mitra, C. A. Gleason, A. Edwards et al., "A $\mathrm{Ca}^{2+}$ / calmodulin-dependent protein kinase required for symbiotic nodule development: gene identification by transcript-based cloning," Proceedings of the National Academy of Sciences of the United States of America, vol. 101, no. 13, pp. 4701-4705, 2004. 

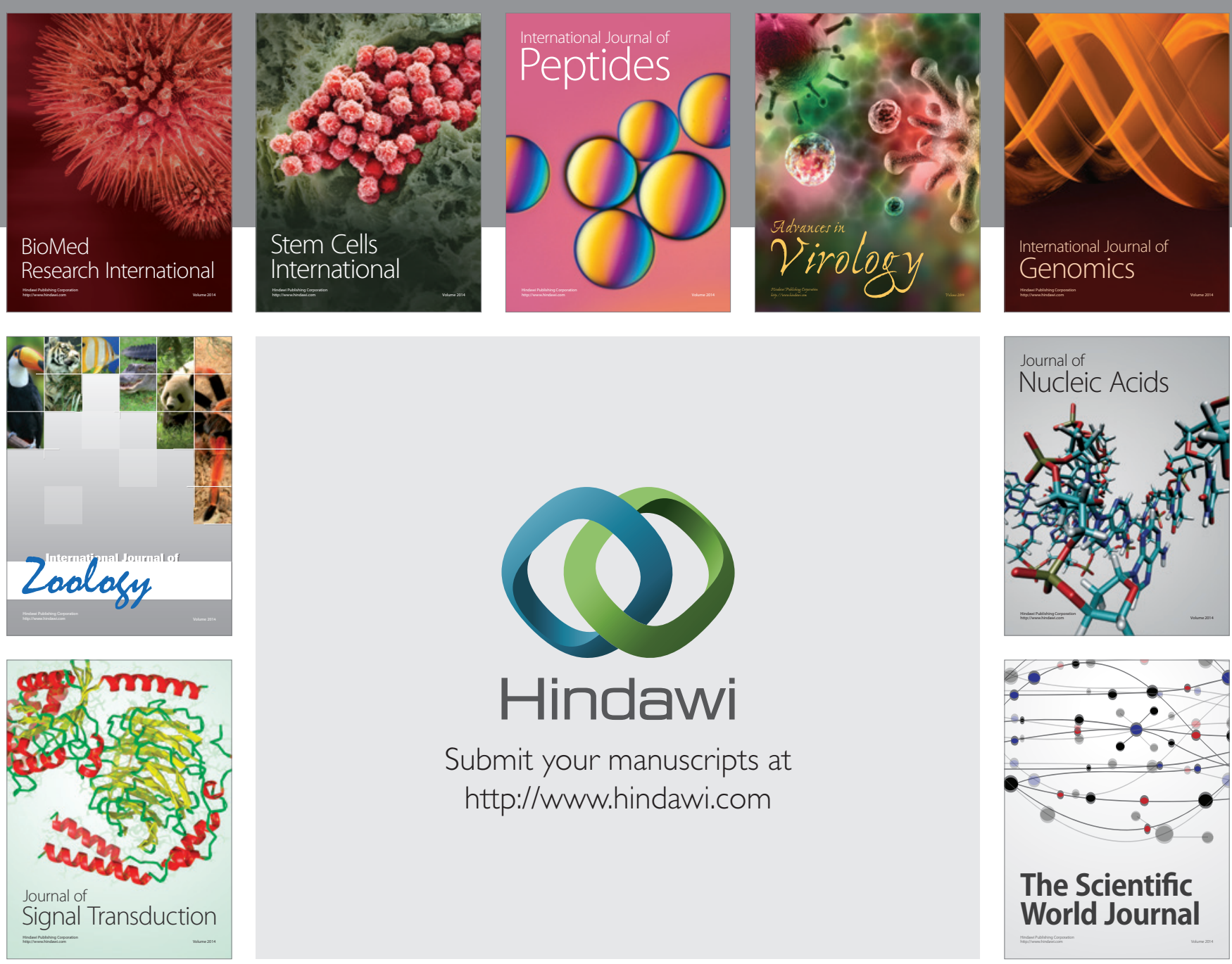

Submit your manuscripts at

http://www.hindawi.com
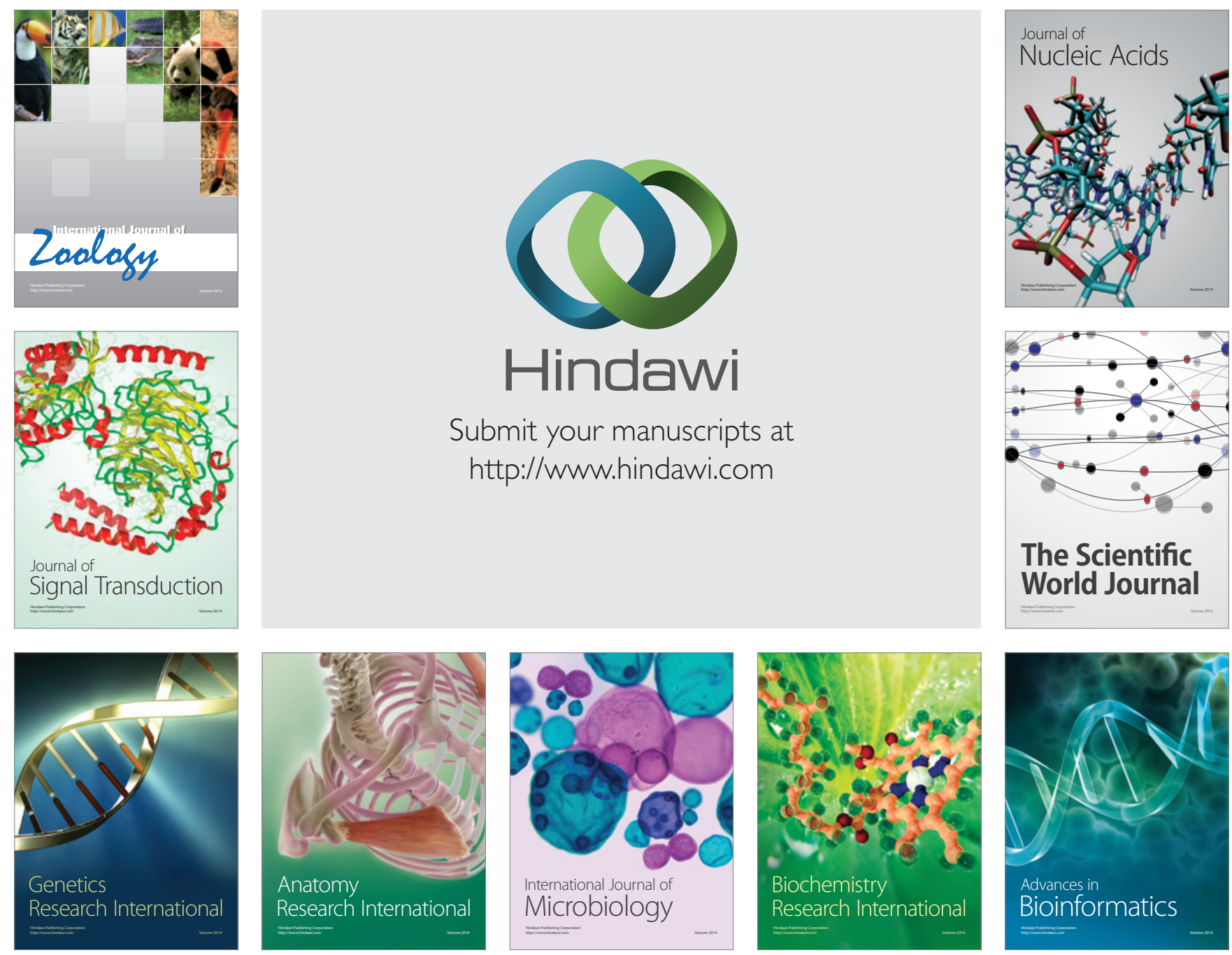

The Scientific World Journal
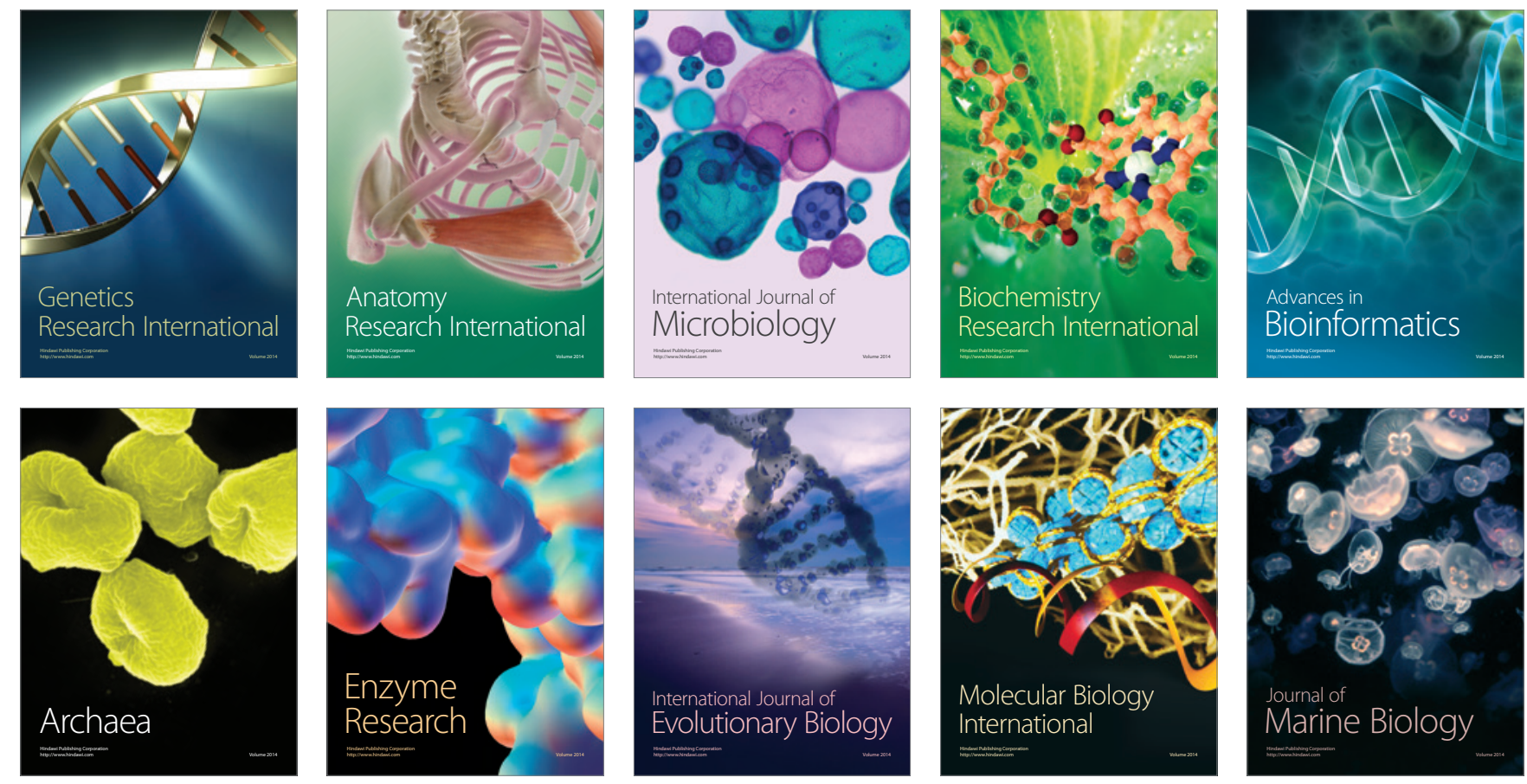